\title{
Correlation of PD-L1 Expression on Tumour Cells Between Diagnostic Biopsies and Surgical Specimens of Lung Cancer in Real Life With Respect to Biopsy Techniques and Neoadjuvant Treatment
}

Daniela Gompelmann ( $\nabla$ daniela.gompelmann@meduniwien.ac.at )

Medical University of Vienna: Medizinische Universitat Wien https://orcid.org/0000-0002-4857-9854

Katharina Sinn

Medical University of Vienna: Medizinische Universitat Wien

Jonas Brugger

Medical University of Vienna: Medizinische Universitat Wien

Dominik Bernitzky

University of Vienna: Universitat Wien

Berta Mosleh

Medical University of Vienna: Medizinische Universitat Wien

Helmut Prosch

Medical University of Vienna: Medizinische Universitat Wien

Silvana Geleff

Medical University of Vienna: Medizinische Universitat Wien

Alissa Blessing

Medical University of Vienna: Medizinische Universitat Wien

Andreas Tiefenbacher

Medical University of Vienna: Medizinische Universitat Wien

Konrad Hoetzenecker

Medical University of Vienna: Medizinische Universitat Wien

Marco Idzko

Medical University of Vienna: Medizinische Universitat Wien

Mir Alireza Hoda

Medical University of Vienna: Medizinische Universitat Wien

\section{Research Article}

Keywords: lung cancer, PD-L1 expression, Immunotherapy, Biopsy 
Posted Date: February 16th, 2022

DOI: https://doi.org/10.21203/rs.3.rs-1343897/v1

License: (c) (i) This work is licensed under a Creative Commons Attribution 4.0 International License. Read Full License 


\section{Abstract}

Purposes: Programmed death-ligand 1 (PD-L1) testing is performed mainly on biopsy specimens in patients with advanced lung cancer. It is questionable whether the small amount of tissue analysed in biopsies may represent the true PD-L1 expression of a tumour.

Methods: In this retrospective study, PD-L1 expression on tumour cells derived from bronchoscopy brush cytology, endobronchial-ultrasound guided transbronchial needle aspiration (EBUS-TBNA), endobronchial biopsy, transbronchial biopsy (TBB) and computed tomography (CT)-guided transthoracic biopsy was compared to the PD-L1 expression of the corresponding surgical resection in lung cancer patients with regard to neoadjuvant treatment in-between.

Results: A quantitative comparison between the diagnostic biopsy of the primary tumour with corresponding resected surgical specimens in a total of 113 lung cancer patients (60\% male, mean age $65 \pm 9$ years) revealed a statistically significant correlation of PD-L1 expression on tumour cells ( $r=0.58$, $\mathrm{p}<0.001)$, for patients without neoadjuvant treatment in-between and for patients who underwent neoadjuvant treatment (both $\mathrm{p}<0.001$ ). Using a cut-off value of $\geq 50 \%$ PD-L1 TPS for comparing the biopsy samples and resected specimens, the concordance rate was $78 \%$ with a Cohen's Kappa of 0.45 .

Conclusion: A statistically significant concordance for PD-L1 expression on tumour cells between biopsies from primary lung tumour and resected specimen was found, but of uncertain clinical accuracy. The use of a cut-off value of $\geq 50 \%$ PD-L1 TPS resulted only in a moderate agreement. Therefore, the interpretation of the PD-L1 determined form biopsy specimens status should only be considered with caution for treatment decisions.

\section{Introduction}

Lung cancer is the leading cause of cancer death worldwide among both men and women. The prognosis is mostly determined by disease stage and treatment. Due to newer therapeutic modalities, particularly the molecular targeted therapy and immunotherapy, survival rates have improved in the recent years [1].

For responsiveness to immunotherapy, the expression of programmed death-ligand 1 (PD-L1) on tumour cells was found to be predictive for immunotherapy efficacy [2-6]. The greatest benefit in first-line treatment is observed in patients with advanced NSCLC who have PD-L1 expression on $\geq 50 \%$ of tumour cells $[5 ; 6]$. Therefore, PD-L1 testing seems to play a significant role in guiding therapy. Although it must be noted that the results of the various trials, which evaluated predictors for immunotherapy, are controversial, and the association with treatment response varies among different immune checkpoint inhibitors (ICl) [7].

As a large proportion of patients with lung cancer present with inoperable status at the time of diagnosis, PD-L1 testing is performed mainly on biopsy specimens and not on surgical specimens. However, it is questionable whether the small amount of tissue analysed in biopsies may represent the PD-L1 
expression, as the majority of tumours demonstrate a considerable intra-tumoural heterogeneity in PD-L1 expression [8]. Therefore, the question of the reliability of their evaluation in biopsies as compared with corresponding resected surgical specimens was raised. Various trials comparing PD-L1 expression in biopsy and matched surgical specimens revealed controversial results [9-13]. Some authors described a poor correlation of PD-L1 expression on tumour cells between biopsy and corresponding surgical specimens [8; 9], whereas other studies found a good concordance of PD-L1 testing between biopsy samples and matches resected specimens [11-14].

In these trials however, it remains unclear whether the biopsy specimens were derived from metastatic lymph nodes instead of primary lung tumours and whether the patients received a neoadjuvant treatment between the biopsy and surgical resection. These uncertainties and controversial statements may lead clinicians to doubt the suitability of small biopsy specimens for PD-L1 testing.

Moreover, it must be noted that PD-L1 expression on tumour cells may vary due to chemotherapy or immunotherapy which was performed between the initial biopsy and the surgical resection. Clinical trials described a downregulation of the PD-L1 expression of tumour cells after a cisplatin-gemcitabine combination, paclitaxel-based regimen or TKI (tyrosine kinase inhibitor)-based therapy [15; 16]. However, in these trials only bronchoscopy samples were compared to surgical specimens so that a possible impact of other sample technique was not taken into account.

Based on these controversial and still unclear results, the goal of this study was to compare the PD-L1 expression on tumour cells of specimens acquired by various diagnostic biopsy techniques and surgical specimens with consideration of the neoadjuvant therapy.

\section{Methods}

The primary endpoint of this retrospective study was the comparison of PD-L1 expression on tumour cells in biopsy specimen of the primary tumour and corresponding surgical specimen with respect to the biopsy technique and the neoadjuvant treatment that was performed in a subset of this patient cohort.

Patients with the diagnosis of lung cancer assessed by biopsy who underwent surgical resection in 20192020 at the Medical University of Vienna were enrolled in this retrospective study. The database queried for this study included the pathological, bronchoscopic, radiological, oncological and surgical reports. The ethics committee of the Medical University of Vienna approved the protocol of this study $(1071 / 2021)$.

\section{Subjects and diagnostic procedures}

Patients with suspicious pulmonary lesions underwent bronchoscopy or computed tomography (CT)guided biopsy for establishing histological diagnosis. Thereby, the bronchoscopy techniques included endobronchial biopsy, endobronchial ultrasound guided transbronchial needle aspiration (EBUS-TBNA), transbronchial biopsy (TBB) using forceps $(n=33)$ and/or brush cytology $(n=31)$. Different techniques 
were combined in several patients for histological diagnosis and/or mediastinal staging. For the comparison of the histology and PD-L1 expression between diagnostic biopsy and surgical regimen, only the PD-L1 expression on tumour cells of the primary tumour but not of lymph node metastases or distant metastases was used. Patients of whom the PD-L1 testing was only available from metastases were excluded from this study.

\section{Evaluation of PD-L1 expression on tumour cells}

Pathological reports were collected for histology and evaluation of PD-L1 expression on tumour cells in biopsy and surgical specimens. All specimens were assessed and scored by experienced pathologists as part of routine diagnostic workup. The histology of the diagnostic biopsies was assessed in 10 different pathology departments using different antibodies for PD-L1 staining, whereas the pathological workup of the surgical specimens was performed only at the Medical University of Vienna. PD-L1 tumour proportion score (TPS) was determined. Based on the PD-L1 expression on tumour cells (TPS) patients were divided in 2 subgroups: PD-L1 expression on $\geq 50 \%$ of tumour cells and $<50 \%$ of tumour cells.

\section{Statistical analysis}

To assess the agreement between PD-L1 measurements of the biopsy and surgical specimen spearman correlation coefficients were calculated. To investigate if the correlation depends on the therapy that patients underwent between biopsy and surgery, scatterplots were drawn with regard to different approaches in preoperative therapy. Spearman correlation coefficients between PD-L1 measurements were calculated separately for patients undergoing chemotherapy, possibly in combination with another form of treatment, and patients without additional therapy between biopsy and surgical resection.

To compare results of the number of times PD-L1 concentrations exceeded the critical bound $(\geq 50 \%)$ a fourfold table was created and Cohen's Kappa was calculated to assess the agreement between measurements of biopsy and corresponding surgical resection. Spearman correlation coefficients and, in case enough patients were available, their $95 \%$-confidence intervals were computed for subpopulations to investigate whether the correlation is different in certain subgroups. Significance level was set to $a=0.05$ for all tests, however, no correction for multiple testing was done, therefore $p$-values are of descriptive hypothesis-generating character. Statistical analyses were performed using R, version 3.6.1 or higher.

\section{Results}

In this retrospective trial, a total of 113 patients (60\% male, mean age $65 \pm 9$ years) with lung cancer of whom PD-L1 expression on tumour cells were available in biopsy specimens and surgical specimens were enrolled in this study.

For establishing the diagnosis, CT-guided biopsy or bronchoscopy was performed in 36\% (41/113) and in $64 \%(72 / 113)$ of patients, respectively. CT guided biopsies were performed in cutting needle technique using an 18-gauge cutting needle and a 17-gauge coaxial needle. The bronchoscopy techniques included endobronchial biopsy $(n=29)$, EBUS-TBNA $(n=12)$, TBB $(n=33)$ and/or brush cytology $(n=31)$. 
The histological work-up of biopsy specimens are presented in Table 1. Most of patients had an adenocarcinoma (60.5\%) followed by squamous cell carcinoma (31.6\%). One patient experienced synchronous carcinoma: a squamous cell carcinoma in the left upper lobe and an adenocarcinoma in the right upper lobe resulting in a total of 114 histological results in 113 patients. 
Table 1

Patient characteristics, biopsy techniques, histology, PD-L1 expression and neoadjuvant therapeutic regimen.

\begin{tabular}{|c|c|}
\hline & Study cohort \\
\hline Patient characteristics & $n=113$ \\
\hline Male $(\%, n)$ & $60 \%(71)$ \\
\hline Age & $65 \pm 9$ \\
\hline Biopsy techniques & $n=146$ \\
\hline Brush cytology $(\%, n)$ & $21.2 \%(31)$ \\
\hline Endobronchial biopsy $(\%, n)$ & $19.9 \%(29)$ \\
\hline EBUS-TBNA $(\%, n)$ & $8.2 \%(12)$ \\
\hline TBFB $(\%, n)$ & $22.6 \%(33)$ \\
\hline CT-guided biopsy $(\%, n)$ & $28.1 \% 41$ \\
\hline Histology derived from biopsy & $n=114$ \\
\hline Adenocarcinoma $(\%, \mathrm{n})$ & $60.5 \%(69)$ \\
\hline Squamous cell carcinoma $(\%, n)$ & $31.6 \%(36)$ \\
\hline Adenosquamous carcinoma $(\%, n)$ & $3.5 \%(4)$ \\
\hline Large cell/neuroendocrine carcinoma $(\%, n)$ & $0.9 \%(1)$ \\
\hline Carcinoid & $0.9 \%(1)$ \\
\hline NSCLC NOS & $2.6 \%(3)$ \\
\hline PD-L1 expression on tumour cells derived from biopsies specimens & $n=114$ \\
\hline$\triangle \mathrm{TPS}(\%)$ & $27.9 \pm 32.6 \%$ \\
\hline TPS $\geq 50 \%(\%, n)$ & $68.4 \%(78)$ \\
\hline TPS $<50 \%(\%, n)$ & $31.6 \%(36)$ \\
\hline Neoadjuvant therapeutic regimen & $\mathrm{n}=27$ \\
\hline Chemotherapy alone & $74.1 \%(20)$ \\
\hline Chemotherapy and immunotherapy & $14.8 \%(4)$ \\
\hline Chemotherapy and radiation therapy & $11.1 \%(3)$ \\
\hline
\end{tabular}


In 104 out of 114 (91.2\%) matched histological pairs of biopsy and surgical specimen, a similar histology diagnosis was established, whereas in 10 out of 114 (8.8\%) matched histological pairs, a change of histology diagnosis was observed: adenosquamous cell carcinoma to squamous cell carcinoma in 2 patients and to adenocarcinoma in 2 patients; NOS (not otherwise specified) to adenocarcinoma in 2 patients and to squamous cell carcinoma in 1 patients; large cell carcinoma to combined large cell carcinoma and squamous cell carcinoma in 1 patient; adenocarcinoma to squamous cell carcinoma in 1 patient and to adenosquamos cell carcinoma in 1 patient.

In $24 \%(27 / 113)$ of the cases, patients underwent neoadjuvant treatment: chemotherapy alone $(n=20)$, chemotherapy plus immunotherapy $(n=4)$, chemotherapy plus radiation therapy $(n=3)$. Chemotherapy consisted of cisplatin-based regimen or carboplatin-based regimen in 13 and 14 patients, respectively. For immunotherapy, 3 patients received pembrolizumab and 1 patient nivolumab. Patient characteristics are presented in Table 1.

\section{Comparison of PD-L1 expression between biopsy and surgical specimen}

PD-L1 testing in 114 biopsy specimens revealed a mean expression of $27.9 \pm 32.6 \%$ and in surgical specimens $21.9 \pm 28.6 \%$ on tumour cells. Quantitative comparison between the diagnostic biopsy of the primary tumour with the corresponding resected surgical specimen revealed a significant correlation $(r=0.58)$ of PD-L1 expression on tumour cells $(p<0.001)$. Results are demonstrated in figure 1.

TPS was found to be $\geq 50 \%$ and $<50 \%$ in $68 \%$ (78/114) and $32 \%$ (36/114) diagnostic biopsies, respectively, and $22 \%(25 / 114)$ and $78 \%(89 / 114)$ in surgical specimens, respectively. In 89 cases, there was a concordance in PD-L1 testing with a cut-off value of $\geq 50 \%$ between biopsy and surgical specimen resulting in a concordance rate of $78 \%$. In 25 out of 114 (21.9\%) cases there was a discordance. The overall agreement was found to moderate with a Cohen's Kappa of 0.45 .

The comparison of PD-L1 expression between biopsy specimens with corresponding surgical specimens that were both only assessed in one pathology department $(n=41)$ using always the same antibodies (BioSite, Klon BSR90) for staging revealed similar results. Quantitative comparison between the biopsy and resected surgical specimen revealed a significant correlation $(r=0.68)$ of PD-L1 expression on tumour cells $(p<0.001)$. Using cut-off value of $\geq 50 \%$ PD-L1 TPS, a fair agreement with a Cohen's Kappa of 0.38 was found.

\section{Impact of biopsy tool}

In a sub-analysis the impact of the biopsy tool on the concordance with the PD-L1 testing of the resected tumour was investigated. For brush cytology, endobronchial biopsy, EBUS-TBNA and CT-guided transthoracic biopsy, a statistically significant correlation of PD-L1 expression on tumour cells between the biopsies and surgical specimens were found (Table 2), whereby a superior correlation was found for 
endobronchial biopsies. Only for the TBB, there was no significant correlation of PD-L1 status between surgically resected specimens and matched biopsy specimens.

Table 2

Correlation of PD-L1 testing between biopsies and surgical specimens with regard to biopsy technique.

\begin{tabular}{|lcl|}
\hline Biopsy technique & $\mathbf{n}$ & $\begin{array}{l}\text { Correlation of PD-L1 TPS } \\
\text { Values }(95 \% \text { Cl) }\end{array}$ \\
\hline Brush cytology & 31 & $0.529[0.241 ; 0.744)$ \\
\hline Endobronchial biopsy & 29 & $0.793[0.6 ; 0.898]$ \\
\hline EBUS-TBNA & 12 & $0.786[0.387 ; 0.937]$ \\
\hline TBB & 33 & $0.308[-0.04 ; 0.589]$ \\
\hline CT-guided transthoracic biopsy & 41 & $0.612[0.375 ; 0.774]$ \\
\hline $\begin{array}{l}\text { EBUS-TBNA = endobronchial ultrasound guided transbronchial needle aspiration. TBB = } \\
\text { transbronchial biopsy. }\end{array}$ & \\
\hline
\end{tabular}

\section{Impact of neoadjuvant treatment}

Correlation of PD-L1-expression on tumour cells between biopsy and surgical specimens in the subgroup of patients undergoing neoadjuvant treatment was $0.74(p<0.001)$. For patients who did not receive neoadjuvant treatment, the correlation was $0.61(p<0.001)$. Scatterplots demonstrate the correlation regarding neoadjuvant treatment (figure 2).

\section{Discussion}

Immunotherapy improves the survival in patients with advanced lung cancer. Data suggest that a high expression of PD-L1 on tumour cells is associated with a superior response to treatment with ICI [2-6]. Therefore, evaluation of PD-L1 expression on tumour cells may help to select patients who will benefit from immunotherapy providing an individualized therapeutic approach.

As most patients with lung cancer present with advanced inoperable disease at the time of diagnosis, PDL1 testing is performed mainly on biopsy specimens. Therefore, our study examined whether the small amount of tissue analysed in biopsies my represent the PD-L1 expression of the tumour depending on biopsy technique and neoadjuvant treatment. Our results indicated a statistically significant but not necessarily clinically relevant correlation between PD-L1 expression on the tumour cells of diagnostic biopsy of the primary tumour with corresponding resected surgical specimens. This is particularly evident when looking at the comparison using a cut-off of $\geq 50 \%$ PD-L1 TPS that resulted only in a moderate agreement. Focusing on biopsy technique, a superior concordance for PD-L1 testing was observed for endobronchial biopsies, an inferior concordance for TBB. 
Various studies comparing PD-L1 status of biopsy and surgical specimen resulted in controversial results. Kitazono and colleagues who compared PD-L1 expression between biopsy from the primary tumour and matched surgical specimens in 79 lung cancer patients, confirmed a significant association of the PD-L1 expression in tumour cells between biopsies and resected tumours [11]. A concordance rate of PD-L1 status was found to be $92.4 \%$ that is superior to our reported concordance rate of $78 \%$. However, while Kitazono et al. used a hybrid score to describe PD-L1 expression on tumour cells and differed between PD-L1 positivity and PD-L1 negativity, we used a cut-off value of 50\% PD-L1 TPS. It must be noted that the interpretation of PD-L1 staining is a challenge for pathologists. PD-L1

immunohistochemistry using a cut-off value is considered to be more challenging than a simple positive or negative result.

In another study which compared PD-L1 expression on tumour cells in different cytology, biopsy and surgical specimens of primary tumours or metastases (lymph node metastases, distant metastases, pleural effusions) in 23 patients independent of treatment in-between, no significant difference between the percentage of PD-L1 positive cytology and histology specimens was found suggesting a good concordance. However, this result was somehow surprising and contrary to findings by Xu et al. who described a poor correlation for PD-L1 expression between primary tumours and metastatic lymph nodes in 76 NSCLC patients [17]. In our study, only biopsy specimens from primary tumours were compared to corresponding resected tumours.

In contrast to our finding, other studies revealed a poor concordance for PD-L1 expression between biopsy and surgical specimen. Ilie and colleagues who used a scoring system from 0 to 3 depending on PD-L1 expression ( $\geq 50 \%, \geq 5 \%$ and $<50 \%, \geq 1 \%$ and $<5 \%,<1 \%$ ) reported a poor correlation between the PD-L1 expression assessed in biopsy specimens and the corresponding resected tumour in 160 patients with NSCLC [9]. In this study, biopsy samples were derived from bronchoscopy including EBUS-TBNA or CT-guided transthoracic biopsy, but it remains unclear, whether the biopsy was sampled from the primary tumour or lymph node metastases. Also Li et al. found only a moderate correlation of PD-L1 expression between whole sections from NSCLCs and the corresponding tissue microarrays (TMAs) serving as surrogate biopsy specimens [10]. Of note, in this study, no real biopsy specimens but TMA were used for comparison.

Previously, different studies reported that a cisplatin-gemcitabine combination, paclitaxel-based regimen or TKI-based therapy led to a downregulation of the PD-L1 expression of tumour cells [15; 16]. In our study however, a statistical significant correlation of PD-L1 expression between biopsy and surgical specimen was not only found in treatment-naïve surgical patients, who did not undergo a treatment inbetween but also in patients who received neoadjuvant therapy.

The limitation of this study is its retrospective character and the relatively small sample size. Particularly the number of patients who underwent neoadjuvant treatment between the biopsy and the surgical resection is low and does not allow a general statement about concordance of PD-L1 expression between biopsy and surgical samples in this subgroup. Another limitation is, that the histological workup of the 
biopsy specimen was performed in different pathology units that used different antibodies for staining (BioSite, Klon BSR90, SP263, QR1, Biocare CAL10 and 22C3 pharmDx). However, a good agreement rate in interpretation of the PD-L1 expression using various antibodies is described [18]. Moreover, similar results were obtained when regarding only at PD-L1 testing of biopsy and surgical specimens using the same antibody in one pathological department. Therefore, the use of various antibodies for staining in different pathology departments seem not to have substantial impact. It must be noted, that our study in comparison to the other study reflects the real-life situation. The demonstration of a statistically significant correlation in this study is even more significant because it is known that interpretation of PDL1 expression does have its peculiarities with varying interobserver agreement.

Summarizing, this study found a statistically significant correlation for PD-L1 expression on tumour cells between biopsy and surgical specimen, but of uncertain clinical relevance. Particular the use of a cut-off value of $\geq 50 \%$ PD-L1 TPS resulted only in a moderate agreement. Therefore, the interpretation of biopsy based PD-L1 status should be considered with caution when deciding therapeutic approach for a patient.

\section{Abbreviations}

EBUS-TBNA endobronchial-ultrasound guided transbronchial needle aspiration

ICl immune checkpoint inhibitor

NSCLC non-small cell lung cancer

PD-L1 programmed death-ligand 1

TBB transbronchial biopsy

TKI tyrosine kinase inhibitor

TMA tissue microarrays

\section{Declarations}

\section{Funding}

The authors declare that no funds, grants, or other support were received during the preparation of this manuscript.

\section{Competing Interests}

The authors have no competing interests to declare that are relevant to the content of this article.

\section{Author Contributions}


All authors contributed to the study conception and design. Material preparation and data collection were performed by Daniela Gompelmann, Katharina Sinn, Dominik Bernitzky, Berta Mosleh and Mir Alireza Hoda. Statistical analysis was performed by Jonas Brugger. The first draft of the manuscript was written by Daniela Gompelmann and all authors commented on previous versions of the manuscript. All authors read and approved the final manuscript.

\section{Data Availability}

The datasets generated during and/or analysed during the current study are available from the corresponding author on reasonable request.

\section{Ethics approval}

This study was performed in line with the principles of the Declaration of Helsinki. Approval was granted by the Ethics Committee of the Medical University of Vienna (EK Nr: 1071/2021) on 10 ${ }^{\text {th }}$ March 2021.

\section{Consent to participate}

This retrospective study was conducted retrospectively from data obtained for clinical purposes. Informed consent for this retrospective study was not required as the research involves no more than minimal risk to the subjects.

\section{Consent to publish}

This publication does not contain any individual person's data in any form.

\section{Acknowledgments}

None

\section{References}

1. Howlader N, Forjaz G, Mooradian MJ, Meza R, Kong CY, Cronin KA, Mariotto AB, Lowy DR, Feuer EJ. The Effect of Advances in Lung-Cancer Treatment on Population Mortality. N Engl J Med. 2020 Aug 13;383(7):640-649. doi: 10.1056/NEJMoa1916623.

2. Herbst RS, Baas P, Kim DW, Felip E, Pérez-Gracia JL, Han JY, Molina J, Kim JH, Arvis CD, Ahn MJ, Majem M, Fidler MJ, de Castro G Jr, Garrido M, Lubiniecki GM, Shentu Y, Im E, Dolled-Filhart M, Garon EB. Pembrolizumab versus docetaxel for previously treated, PD-L1-positive, advanced non-small-cell lung cancer (KEYNOTE-010): a randomised controlled trial. Lancet. 2016 Apr 9;387(10027):15401550. doi: 10.1016/S0140-6736(15)01281-7. Epub 2015 Dec 19. PMID: 26712084.

3. Gandini S, Massi D, Mandalà M. PD-L1 expression in cancer patients receiving anti PD-1/PD-L1 antibodies: A systematic review and meta-analysis. Crit Rev Oncol Hematol. 2016 Apr;100:88-98. doi: 10.1016/j.critrevonc.2016.02.001. Epub 2016 Feb 10. PMID: 26895815. 
4. Xia L, Liu Y, Wang Y. PD-1/PD-L1 Blockade Therapy in Advanced Non-Small-Cell Lung Cancer: Current Status and Future Directions. Oncologist. 2019 Feb;24(Suppl 1):S31-S41. doi: 10.1634/theoncologist.2019-IO-S1-s05. PMID: 30819829; PMCID: PMC6394772.

5. Fehrenbacher L, Spira A, Ballinger M, Kowanetz M, Vansteenkiste J, Mazieres J, Park K, Smith D, Artal-Cortes A, Lewanski C, Braiteh F, Waterkamp D, He P, Zou W, Chen DS, Yi J, Sandler A, Rittmeyer A; POPLAR Study Group. Atezolizumab versus docetaxel for patients with previously treated nonsmall-cell lung cancer (POPLAR): a multicentre, open-label, phase 2 randomised controlled trial. Lancet. 2016 Apr 30;387(10030):1837-46. doi: 10.1016/S0140-6736(16)00587-0. Epub 2016 Mar 10. PMID: 26970723.

6. Gandhi L, Rodríguez-Abreu D, Gadgeel S, Esteban E, Felip E, De Angelis F, Domine M, Clingan P, Hochmair MJ, Powell SF, Cheng SY, Bischoff HG, Peled N, Grossi F, Jennens RR, Reck M, Hui R, Garon EB, Boyer M, Rubio-Viqueira B, Novello S, Kurata T, Gray JE, Vida J, Wei Z, Yang J, Raftopoulos H, Pietanza MC, Garassino MC; KEYNOTE-189 Investigators. Pembrolizumab plus Chemotherapy in Metastatic Non-Small-Cell Lung Cancer. N Engl J Med. 2018 May 31;378(22):2078-2092. doi: 10.1056/NEJMoa1801005. Epub 2018 Apr 16. PMID: 29658856.

7. Brahmer J, Reckamp KL, Baas P, Crinò L, Eberhardt WE, Poddubskaya E, Antonia S, Pluzanski A, Vokes EE, Holgado E, Waterhouse D, Ready N, Gainor J, Arén Frontera O, Havel L, Steins M, Garassino MC, Aerts JG, Domine M, Paz-Ares L, Reck M, Baudelet C, Harbison CT, Lestini B, Spigel DR.

Nivolumab versus Docetaxel in Advanced Squamous-Cell Non-Small-Cell Lung Cancer. N Engl J Med. 2015 Jul 9;373(2):123-35. doi: 10.1056/NEJMoa1504627. Epub 2015 May 31. PMID: 26028407; PMCID: PMC4681400.

8. Haragan A, Field JK, Davies MPA, Escriu C, Gruver A, Gosney JR. Heterogeneity of PD-L1 expression in non-small cell lung cancer: Implications for specimen sampling in predicting treatment response. Lung Cancer. 2019 Aug;134:79-84. doi: 10.1016/j.lungcan.2019.06.005. Epub 2019 Jun 5. PMID: 31320000; PMCID: PMC6658831.

9. Ilie M, Long-Mira E, Bence C, Butori C, Lassalle S, Bouhlel L, Fazzalari L, Zahaf K, Lalvée S, Washetine K, Mouroux J, Vénissac N, Poudenx M, Otto J, Sabourin JC, Marquette CH, Hofman V, Hofman P. Comparative study of the PD-L1 status between surgically resected specimens and matched biopsies of NSCLC patients reveal major discordances: a potential issue for anti-PD-L1 therapeutic strategies. Ann Oncol. 2016 Jan;27(1):147-53. doi: 10.1093/annonc/mdv489. Epub 2015 Oct 19. PMID: 26483045.

10. Li C, Huang C, Mok TS, Zhuang W, Xu H, Miao Q, Fan X, Zhu W, Huang Y, Lin X, Jiang K, Hu D, Chen X, Huang P, Lin G. Comparison of 22C3 PD-L1 Expression between Surgically Resected Specimens and Paired Tissue Microarrays in Non-Small Cell Lung Cancer. J Thorac Oncol. 2017 Oct;12(10):15361543. doi: 10.1016/j.jtho.2017.07.015. Epub 2017 Jul 24. PMID: 28751245.

11. Kitazono S, Fujiwara Y, Tsuta K, Utsumi H, Kanda S, Horinouchi H, Nokihara H, Yamamoto N, Sasada S, Watanabe S, Asamura H, Tamura T, Ohe Y. Reliability of Small Biopsy Samples Compared With Resected Specimens for the Determination of Programmed Death-Ligand 1 Expression in Non-- 
Small-Cell Lung Cancer. Clin Lung Cancer. 2015 Sep;16(5):385-90. doi: 10.1016/j.cllc.2015.03.008. Epub 2015 Apr 4. PMID: 25937270.

12. Heymann JJ, Bulman WA, Swinarski D, Pagan CA, Crapanzano JP, Haghighi M, Fazlollahi L, Stoopler MB, Sonett JR, Sacher AG, Shu CA, Rizvi NA, Saqi A. PD-L1 expression in non-small cell lung carcinoma: Comparison among cytology, small biopsy, and surgical resection specimens. Cancer Cytopathol. 2017 Dec;125(12):896-907. doi: 10.1002/cncy.21937. Epub 2017 Oct 12. PMID: 29024471.

13. Tsunoda A, Morikawa K, Inoue T, Miyazawa T, Hoshikawa M, Takagi M, Mineshita M. A prospective observational study to assess PD-L1 expression in small biopsy samples for non-small-cell lung cancer. BMC Cancer. 2019 Jun 7;19(1):546. doi: 10.1186/s12885-019-5773-3. PMID: 31174496; PMCID: PMC6555021.

14. Zhao L, Chen P, Fu K, Li J, Dai Y, Wang Y, Zhuang Y, Sun L, Chen H, Lin Q. Concordance of PD-L1 Status Between Image-Guided Percutaneous Biopsies and Matched Surgical Specimen in Non-Small Cell Lung Cancer. Front Oncol. 2021 Feb 23;10:551367. doi: 10.3389/fonc.2020.551367. PMID: 33708615; PMCID: PMC7940543.

15. Sheng J, Fang W, Yu J, Chen N, Zhan J, Ma Y, Yang Y, Huang Y, Zhao H, Zhang L. Expression of programmed death ligand- 1 on tumor cells varies pre and post chemotherapy in non-small cell lung cancer. Sci Rep. 2016 Jan 29;6:20090. doi: 10.1038/srep20090. Erratum in: Sci Rep. 2016;6:23850. Yanhuang, [corrected to Huang, Yan]. PMID: 26822379; PMCID: PMC4731819.

16. Rojkó L, Reiniger L, Téglási V, Fábián K, Pipek O, Vágvölgyi A, Agócs L, Fillinger J, Kajdácsi Z, Tímár J, Döme B, Szállási Z, Moldvay J. Chemotherapy treatment is associated with altered PD-L1 expression in lung cancer patients. J Cancer Res Clin Oncol. 2018 Jul;144(7):1219-1226. doi: 10.1007/s00432018-2642-4. Epub 2018 Apr 19. PMID: 29675791.

17. Xu H, Chen X, Lin D, Zhang J, Li C, Zhang D, Zhang X. Conformance Assessment of PD-L1 Expression Between Primary Tumour and Nodal Metastases in Non-Small-Cell Lung Cancer. Onco Targets Ther. 2019 Dec 30;12:11541-11547. doi: 10.2147/OTT.S223643. PMID: 31920342; PMCID: PMC6941607.

18. Büttner R, Gosney JR, Skov BG, Adam J, Motoi N, Bloom KJ, Dietel M, Longshore JW, López-Ríos F, Penault-Llorca F, Viale G, Wotherspoon AC, Kerr KM, Tsao MS. Programmed Death-Ligand 1 Immunohistochemistry Testing: A Review of Analytical Assays and Clinical Implementation in NonSmall-Cell Lung Cancer. J Clin Oncol. 2017 Dec 1;35(34):3867-3876. doi:

10.1200/JCO.2017.74.7642. Epub 2017 Oct 20. PMID: 29053400.

\section{Figures}




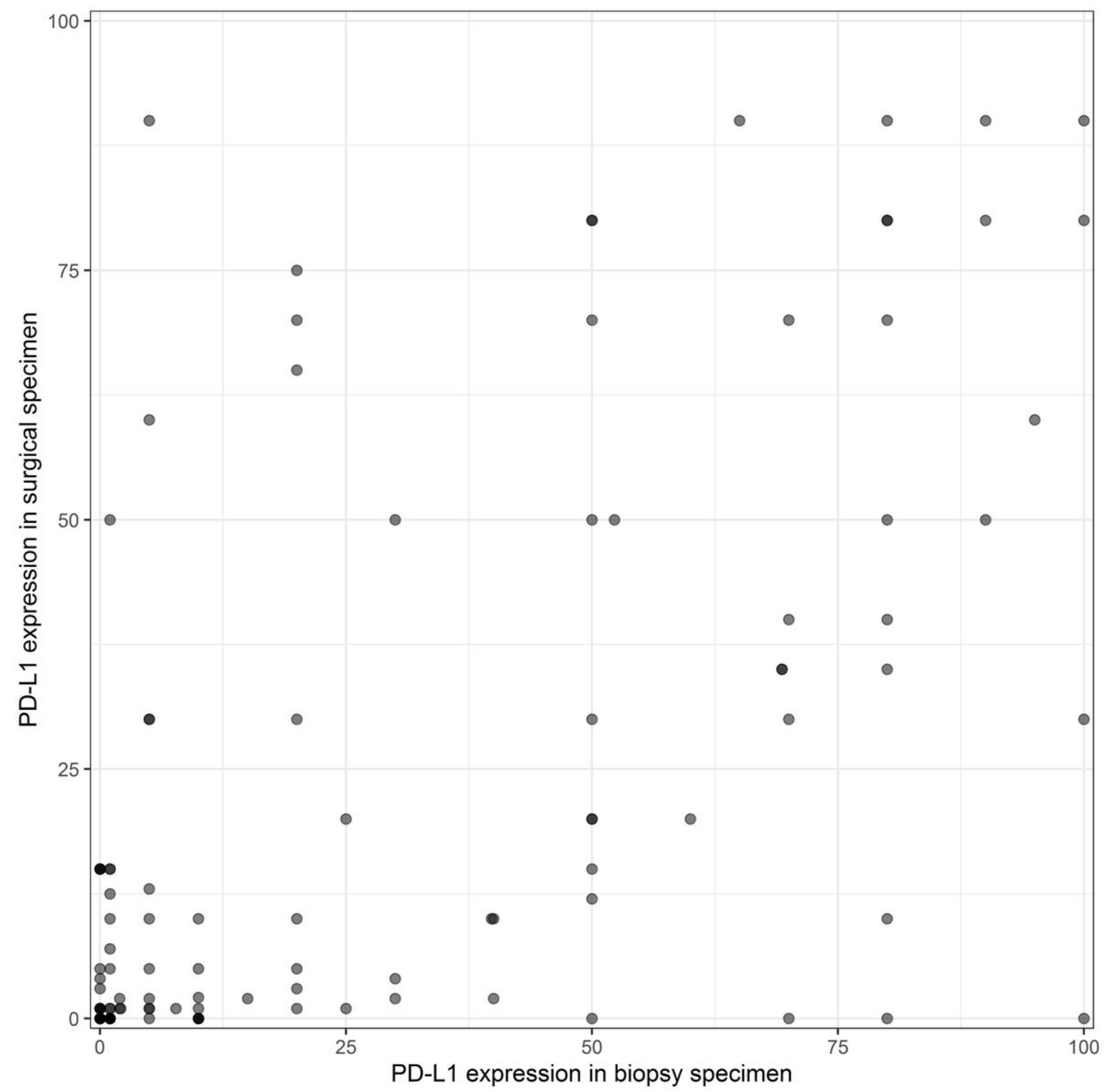

Figure 1

Correlation of PD-L1 testing between biopsies and surgical specimens. 


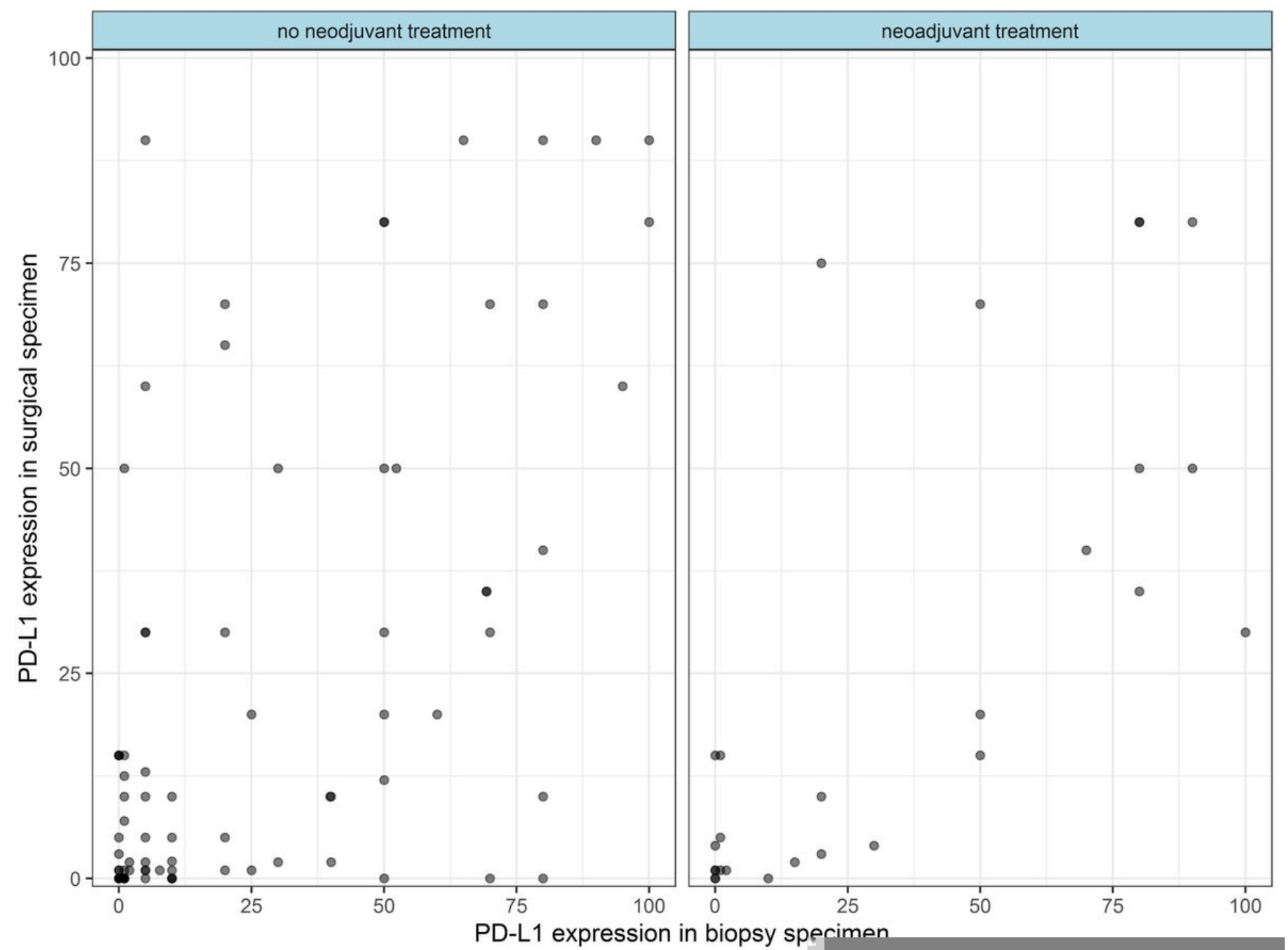

Figure 2

Scatterplots demonstrating the correlation of PD-L1 expression between biopsy and surgical specimens in patients with and without neoadjuvant treatment in-between. 